\title{
EPILEPTIC MANIFESTATIONS INDUCED BY MIDAZOLAM IN THE NEONATAL PERIOD
}

\author{
Maria Augusta Montenegro, Marilisa M. Guerreiro, Jamil Pedro Siqueira Caldas, \\ Maria Valeriana L. Moura-Ribeiro, Carlos Alberto M. Guerreiro
}

\begin{abstract}
Antiepileptic drugs may cause worsening of epilepsy by aggravating pre-existing seizures or by triggering new seizure types. There are several reports of adverse effects related to midazolam, but only a few authors reported epileptic manifestations. We report four newborns seen at the Neonatal Intensive Care Unit of our University Hospital, who developed seizures a few seconds after the administration of midazolam. It is difficult to identify the patients at risk, but it is important to be aware and recognize this situation.
\end{abstract}

KEY WORDS: midazolam, seizures, neonatal period.

\begin{abstract}
Manifestações epilépticas induzidas por midazolam no período neonatal
RESUMO - Drogas antiepilépticas podem piorar o controle da epilepsia por agravar crises epilépticas preexistentes ou por desencadear novos tipos de crises. Existem vários relatos de eventos adversos relacionados ao midazolam; entretanto, poucos autores referem manifestações epilépticas. Neste estudo relatamos a ocorrência de crises epilépticas poucos segundos após a administração de midazolam, em quatro neonatos atendidos na Unidade de Terapia Intensiva do nosso hospital universitário. É difícil determinar quais pacientes estão em risco, mas é importante estar atento e reconhecer esta situação.
\end{abstract}

PALAVRAS-CHAVE: midazolam, crise epiléptica, período neonatal.

Antiepileptic drugs (AED) may cause worsening of epilepsy by aggravating pre-existing seizures or by triggering new seizure types ${ }^{1}$. Precipitation of tonic seizures or tonic status epilepticus by benzodiazepines in patients with generalized epilepsy is rare, but well established ${ }^{2}$.

We report the occurrence of seizures in four newborns, seen at the Neonatal Intensive Care Unit of our University Hospital, a few seconds after being sedated with midazolam.

\section{CASES}

Patient 1. A preterm newborn with gestational age (GA) of 34 weeks and 2 days, Apgar score 3 and 8 in the first and fifth minutes of life, respectively, birth weight $2110 \mathrm{~g}$, was kept in the Neonatal Intensive Care Unit because she developed hypoglycemia in the first hours of life. In the third day of life she presented a seizure (characterized by clonic movements of the four limbs, which did not stop after being restrained, lasting about 2 minutes) a few minutes after midazolam $(0.15 \mathrm{mg} / \mathrm{kg})$ was administered intravenously for sedation (during this event glucose serum level was normal). Neurological examination showed only hypotonia. She had not had any other seizure before this event. Electroencephalogram (EEG) (performed in the $5^{\text {th }}$ day of life) and brain ultrasonography were normal.
After this seizure she has never had any other epileptic manifestation. The follow up period is 4 months.

Patient 2. A preterm newborn with GA of 30 weeks and 4 days, Apgar score 2 and 8 in the first and fifth minutes of life, respectively, birth weight $1070 \mathrm{~g}$, was kept in the Neonatal Intensive Care Unit because he developed respiratory distress. During the first day of life he presented a seizure (characterized by clonic movements of the four limbs, which did not stop after being restrained, lasting about 1 to 2 minutes) a few seconds after midazolam ( 0.15 $\mathrm{mg} / \mathrm{kg}$ ) was administered intravenously for sedation. He had not had any other seizure before and neurologic examination showed hypotonia. Brain ultrasonography was normal. EEG was not performed due to technical problems. After this episode he has never had any other epileptic manifestation. The follow up period is 4 months.

Patient 3. A preterm newborn with GA of 27 weeks and 4 days, Apgar score 1, 5 and 8 in the first, fifth and tenth minutes of life, respectively, birth weight $620 \mathrm{~g}$, was kept in the Neonatal Intensive Care Unit because she developed severe hypoxic ischemic encephalopathy, meningitis and respiratory disturbances. She had already had seizures since the first week of life (characterized by multifocal clonic movements), which were controlled with phenobarbital. Her last seizure was 3 weeks prior to the midazolam administration. In the third month of life (conceptional age of 44 weeks) she presented a seizure (charac-

Department of Neurology, Faculty of Medical Sciences (FMC), University of Campinas (UNICAMP), Campinas SP, Brazil.

Received 29 September 2000, received in final form 21 November 2001. Accepted 28 November 2001.

Dra. Marilisa M. Guerreiro - Departamento de Neurologia - FCM / UNICAMP - Caixa Postal 6111 - $13083-970$ Campinas SP - Brasil. E-mail:guerreir@dglnet.com.br 
terized by clonic movements of the four limbs, which did not stop after being restrained, lasting about 2 minutes) a few seconds after midazolam $(0.15 \mathrm{mg} / \mathrm{kg})$ was administered intravenously for sedation. She needed a second dose of midazolam in the same day, and had another seizure (similar to the one described above) a few seconds after this second injection. Neurologic examination showed microcephaly, hypertonia and hyperactive reflexes. Brain ultrasonography was normal. EEG was not performed due to technical problems. Phenobarbital therapy was continued and after this episode she has never had any other epileptic manifestation. Follow up period is 6 months.

Patient 4. A preterm newborn with GA of 26 weeks, Apgar score 6 and 8 in the first and fifth minutes of life, birth weight $1040 \mathrm{~g}$, was kept in the Neonatal Intensive Care Unit because he developed severe hypoxic ischemic encephalopathy, respiratory disturbances, renal failure and pulmonary infection. He presented seizures (characterized by multifocal clonic movements and tonic posturing of the legs) in the first two days of life probably due to hypoxic ischemic encephalophathy and central nervous system (CNS) hemorrhagic lesions, which were controlled with phenobarbital ( $5 \mathrm{mg} / \mathrm{kg} /$ day). In the $4^{\text {th }}$ day of life he presented a seizure (characterized by clonic movements of the four limbs, which did not stop after being restrained, lasting about 1 minute) a few seconds after midazolam $(0.15 \mathrm{mg} / \mathrm{kg})$ was administered intravenously for sedation. Neurological examination showed hypotonia and absent reflexes, but the patient was sedated with fentanyl when the examination was performed. Brain ultrasonography showed bilateral hemorrhagic lesions. EEG was not performed due to technical problems. Phenobarbital therapy was continued and after this episode he has never had any other epileptic manifestation. He died with 6 days of age.

\section{DISCUSSION}

Midazolam is a benzodiazepine with a short halflife that is used extensively for preoperative and procedure-related sedation ${ }^{3}$. In the neonatal period it seems to have a longer half-life ( 6.25 hours) ${ }^{4}$ and an increase in its use for sedation, as well as an AED, has been observed in neonatal intensive care units.

There are several reports of adverse effects related to midazolam, but only a few authors reported epileptic manifestations ${ }^{5-7}$.

We report four neonates who developed epileptic manifestations a few seconds after the administration of midazolam. Other possible causes of seizures such as hypoglycemia, hypocalcemia, infection, polycitemia, CNS malformations, hemorrhagic or ischemic lesions were investigated. Patient 4 was clinically unstable when the seizure induced by midazolam occurred, but the clear temporal relationship with the administration of midazolam suggests that this event was probably drug related.

Buts et al. ${ }^{7}$ described myoclonic movements of the four limbs observed in six neonates who received con- tinuous intravenous infusion of midazolam, 2-48 hours after the midazolam infusion had been started.

Engstrom ${ }^{5}$ reported a 27 year-old woman presenting a generalized tonic-clonic seizure (lasting 1 - 2 minutes) immediately following the intravenously administration of $2 \mathrm{mg}$ of midazolam for sedation.

Despite the lack of video EEG monitoring during the events presented by our patients, we believe that they are truly epileptic in nature because the physician who witnessed the seizure tested them and the clonic movements could be felt after restraining the limb. Moreover, clonic seizures in the neonatal period consistently show a close relationship to EEG seizure discharges ${ }^{8,9}$.

It should be emphasized that the epileptic manifestations occurred after a short period following the drug administration (usually an intravenous bolus injection) and this should be differentiated from a reversible encephalopathy characterized by poor visual tracking, depression of consciousness and involuntary movements (choreoathetosis) associated with the withdrawal of prolonged intravenous midazolam and fentanyl administration ${ }^{3}$.

There are no explanations why an AED may induce seizures. The relationship between the speed of the infusion and the occurrence of seizure might be a possibility, since it occurred after an intravenous bolus injection. Van den Anker and Sauer ${ }^{6}$ suggested that since midazolam decreases arterial pressure and heart rate in preterm infants, maybe it could be due to a decrease in cerebral blood flow. This hypotesis is speculative and a direct effect on the CNS cannot be excluded. We believe that in our patients the speed of the infusion of midazolam played an important role in the occurrence of this adverse event, because since we slowed down the infusion we have not observed new cases like these.

We conclude that it is difficult to identify the patients at risk, but it is important to be aware and recognize this situation.

\section{REFERENCES}

1. Guerrini R, Belmonte A, Genton P. Antiepileptic drug-induced worsening of seizures in children. Epilepsia 1998;39(Suppl 3):S2-S10.

2. Berkovic SF. Aggravation of generalized epilepsies. Epilepsia 1998; 39(Suppl 3):S11-S14.

3. Bergman I, Steeves M, Burckart G, Thompson A. Reversible neurologic abnormalities associated with prolonged intravenous midazolam and fentanyl administration. J Pediatr 1991;119:644-651.

4. Jacqz-Aigrain E, Wood C, Robieux I. Pharmacokinetics of midazolam in critically ill neonates. Eur J Clin Pharmacol 1990;3:191-192.

5. Engstrom RH. A complication associated with the use of midazolam. Anesthesiology 1989;70:719.

6. Van den Anker JN, Sauer PJJ. The use of midazolam in preterm neonate. Eur J Pediatr 1992;2:152

7. Buts JP, Cadranel S, Deprettere A, et al. Midazolam and myoclonus in neonate. Eur J Pediatr 1994;143:389-390.

8. Mizrahi EM, Kellaway P. Diagnosis and management of neonatal seizures. Philadelphia: Lippincott-Raven 1998:15-34.

9. Mizrahi EM, Kellaway P. Characterization and classification of neonatal seizures. Neurology 1997;37:1837-1844. 